\section{The effect of anosmia on taste preference behavior as a function of deprivation conditions}

\author{
H. E. MARKS*, J. D. SEAGO†, and N. R. REMLEY \\ Texas Christian University, Fort Worth, Tex. 76129
}

Anosmic and normal rats were compared in a single-bottle preference test with regard to the amount of water, sucrose, saccharin, and quinine solutions consumed. Under food deprivation, anosmic rats consumed reliably more water and sucrose and less saccharin and quinine than normal rats; under water deprivation the order of these relationships was reversed.
Previous research has demonstrated reliable differences in learning between anosmic and normal rats (Honzik, 1936; Lindley, 1930). A recent study (Marks, Remley, Seago, \& Hastings, 1969) suggested that there were motivational differences between anosmic and normal rats. Anosmic rats barpressed more on a VI 2-min schedule but were less active in the activity wheel than normal rats. In addition, the anosmic rats' activity levels in the wheels decreased over days, contrary to Marks's (1968) findings with normal rats.

The present study represents an attempt to evaluate possible motivational differences between anosmic and normal rats. Anosmic and normal rats were compared with respect to consumatory preference behavior for four liquids: tap water, sucrose, saccharin, and quinine. In order to evaluate the effects of deprivation on preference behavior, two experiments were performed: the first employed food deprivation, the second, water deprivation. The use of both food and water deprivation conditions was required to investigate the possibility of a deprivationpreference interaction.

$$
\begin{gathered}
\text { EXPERIMENT } 1 \\
\text { Method }
\end{gathered}
$$

The Ss were 11 naive female rats of the Holtzman strain, approximately 85 days old at the start of the experiment. The preoperative weight of the rats varied between 231 and $267 \mathrm{~g}$.

The apparatus consisted of 11 individual Wahmann cages of the same type in which the rats were normally housed in the colony and $12100-\mathrm{ml}$ animal drinking tubes. The solutions were tap water, $10 \%$ sucrose, $0.05 \%$ saccharin, and $0.001 \%$ quinine $\mathrm{HCl}$. The last three solutions were prepared with distilled water on a weight/volume basis.

*Please send reprint requests to $\mathrm{H}$. E. Marks, Department of Psychology, University of Georgia, Athens, Ga. 30601. University of Georgia. + Now at the Department of Psychology.
All rats were housed individually and maintained on ad lib food and water until 7 days following surgery. The rats were divided into two groups: six anosmic and five normal animals. Anosmia was produced by bilateral aspiration of the olfactory bulbs under sodium pentobarbitol (Nembutal) anesthesia. Seven days after surgery all animals were food deprived and reduced to $90 \%$ of their ad lib weight. They were maintained at this weight throughout the experiment.

The amount of solution consumed was measured at $5-\mathrm{min}, 30-\mathrm{min}, 2-\mathrm{h}$, $6-\mathrm{h}$, and 12 -h intervals after the rat was given access to the solution on each of the 4 test days. All animals received water on the first test day as a standard solution. The following 3 days, the rats received the remaining solutions on a randomly assigned basis with two constraints: no more than two animals per group were to receive any single solution on any given day, and each animal was to receive each solution only once. A one-bottle test was used, since pilot work and Vance (1967) found that anosmic animals refused $0.001 \%$ quinine in a two-bottle test and refused water when paired with a $10 \%$ sucrose solution.

The animals were not water deprived, except during the test period when only the test solution was available. No food was available during the test periods, but all animals were fed within $1 \mathrm{~h}$ after the completion of each day's test.

\section{Results}

Histology confirmed that each of the experimental animals had its olfactory bulbs completely transected and had no frontal lobe damage.

Anosmic rats drank more water than did normal rats, although this difference was not reliable until the 6-h measurement interval (Fig. 1). An analysis of variance indicated reliable differences between groups $(p<.05)$ and among measurement intervals $(p<.05)$ for water intake.

Both anosmic and normal rats drank large amounts of the sucrose solution, with the anosmic rats consuming greater amounts by the $30-\mathrm{min}$

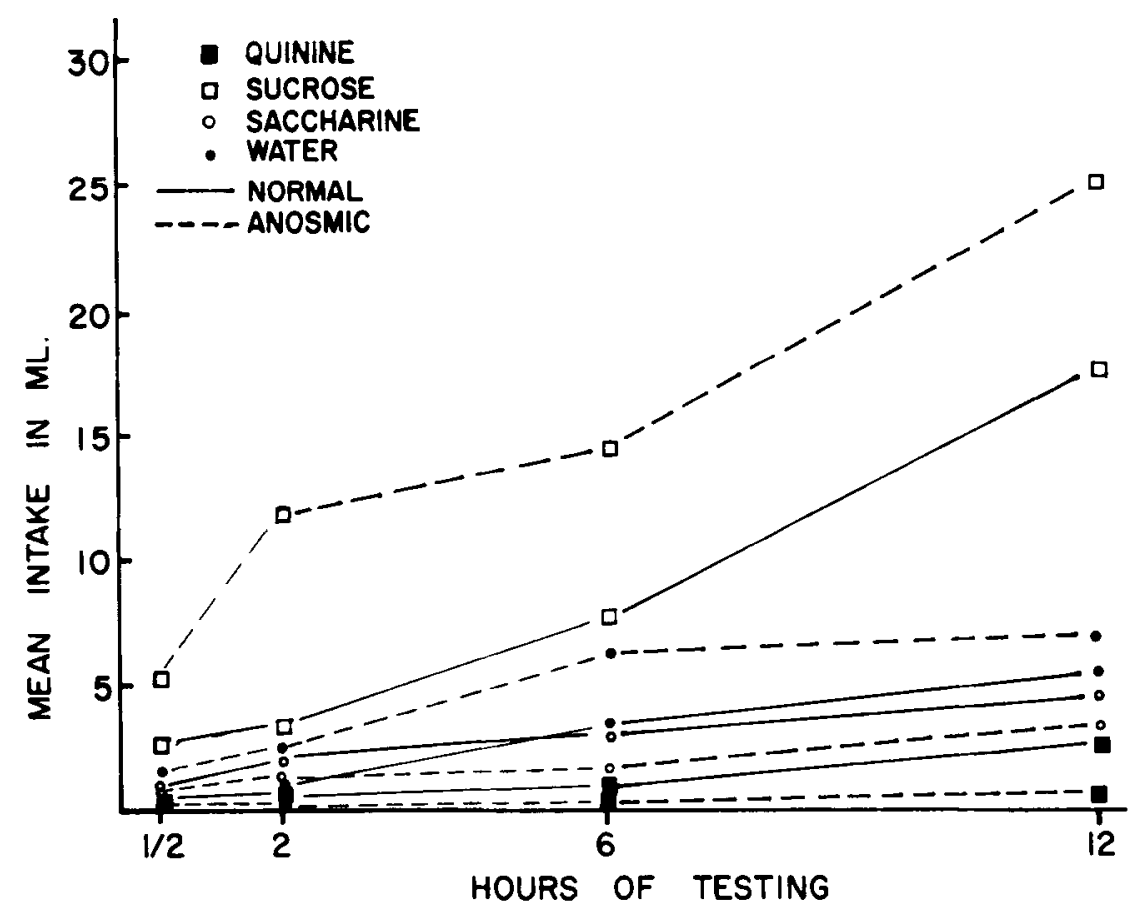

Fig. 1. Mean absolute intake measures of water, sucrose, saccharin, and quinine solutions as a function of food deprivation conditions. The 5 -min measurement interval was omitted since there were no reliable differences at that point. 


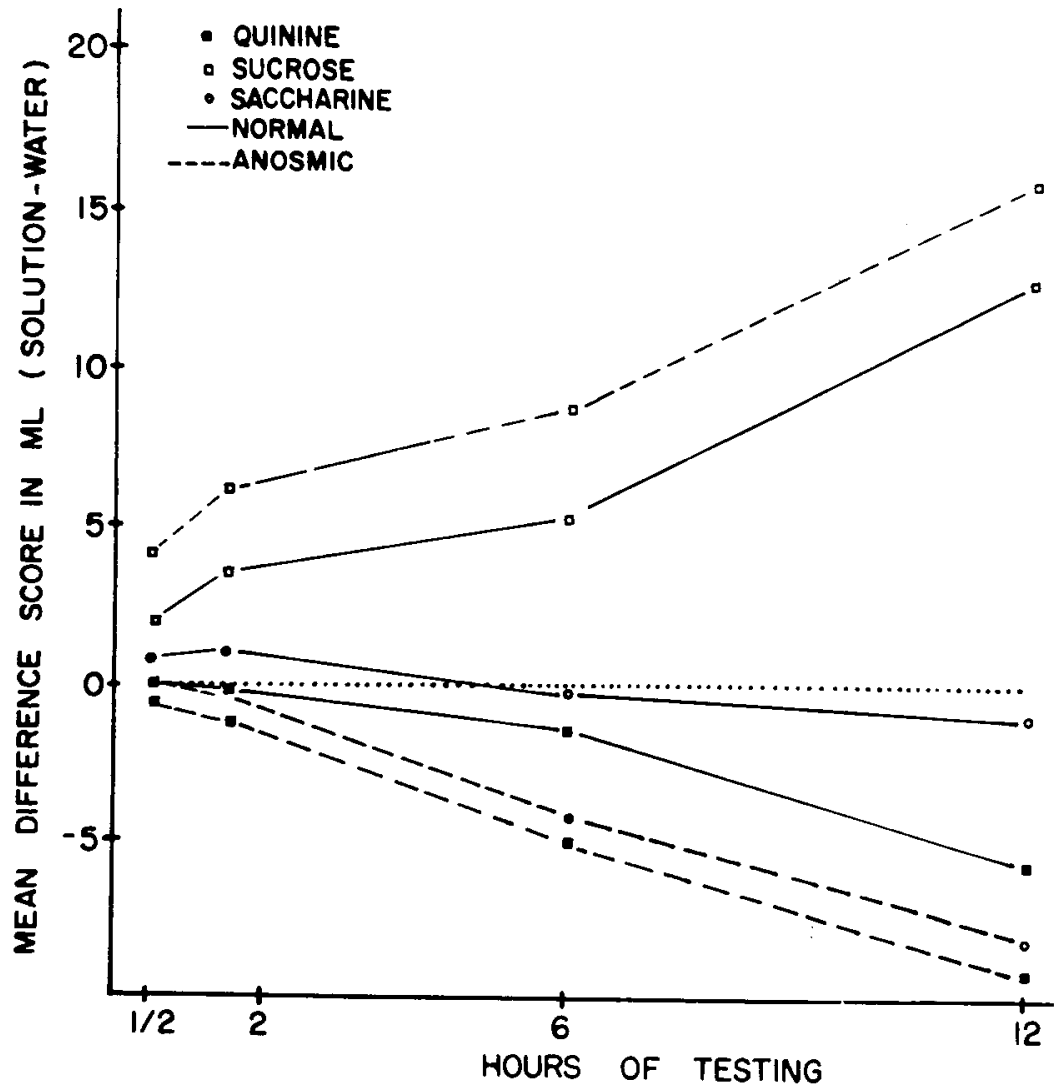

Fig. 2. Mean difference intake measures of sucrose, saccharin, and quinine solutions as a function of food deprivation conditions. The 5-min measurement interval was omitted since there were no reliable differences at that point.

measurement interval. No reliable differences were found between or within groups for quinine and saccharine consumption. Using the amount of water consumed on the first day as a standard, difference scores were computed for each animal for each solution. Difference scores were used in an attempt to eliminate "thirst" as a factor determining the

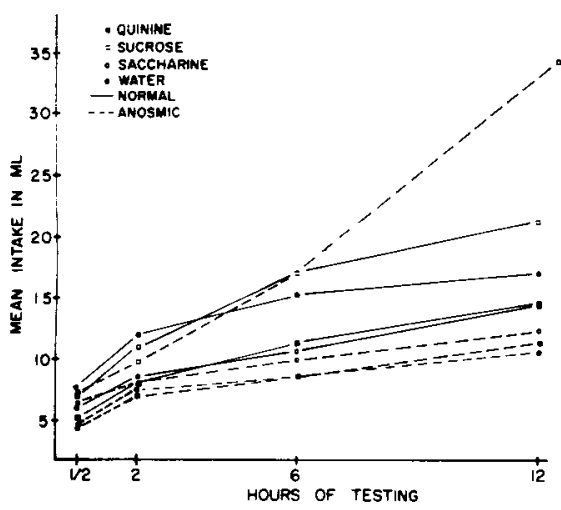

Fig. 3. Mean absolute intake measures of water, sucrose, saccharin and quinine solutions as a function of $12 \mathrm{~h}$ of water deprivation. The 5-min measurement interval was omitted since there were no reliable differences at that point. amount of solution consumed. The analysis of variance of the difference scores indicated that: anosmic rats consumed slightly more, on the whole, than did normal rats $(p<.05)$ consumption increased over time ( $p<.001) ;$ and, while sucrose consumption increased, consumption of the other solutions decreased over time ( $p<.001$, Fig. 2).

\section{EXPERIMENT 2} Method

The Ss were 10 naive female rats of the Holtzman strain, approximately 80 days old at the start of the experiment. The preoperative weight of the rats varied between 227 and $264 \mathrm{~g}$. The testing apparatus and solutions were the same as those used in Experiment 1.

The procedure was identical with that of the first experiment, with the exception of the deprivation conditions. The animals were divided into two groups: five anosmic and five normal rats. Eight days after surgery all rats were water deprived for $12 \mathrm{~h}$ preceding testing. Deprivation was started at 8 p.m., and the animals were tested from 8 a.m. to 8 p.m. the following day. One day of recovery (water available ad lib) followed each testing day. Food was available ad lib in the home cage but was not available in the test cages.
Results

Histology confirmed each of the experimental animals had its olfactory bulbs completely transected bilaterally and had no frontal lobe damage.

Anosmic rats drank less water than did normal rats, although this difference was not reliable until the 6-h measurement interval (Fig. 3). An analysis of variance indicated reliable differences between groups $(p<.05)$ and among measurement intervals $(p<.001)$.

Both anosmic and normal animals drank large amounts of the sucrose solutions, with the anosmic animals consuming larger amounts only at the 12-h measure. Only small inter- and intragroup differences were found for both saccharin and quinine. Difference scores were computed for each animal, as in the first experiment. The analysis of variance of difference scores indicated a significant measurement interval effect $(p<.01)$ and a Solution by Measurement Interval interaction ( $\mathrm{p}<.001$, Fig. 4). DISCUSSION

While the ablation of the olfactory bulbs obviously influences taste preferences in rats, the relationship is by no means a simple one. At least two factors have been shown to play a major role in this relationship. The first is that of the particular deprivation condition. A comparison of Figs. 1 and 3 indicates an almost complete reversal of the order effect of preference between anosmic and normal rats as a function of the deprivation conditions. The mechanism(s) producing this differential effect are unknown. Regardless of the particular mechanism(s) involved, it appears likely that preference behavior cannot be separated from deprivation conditions.

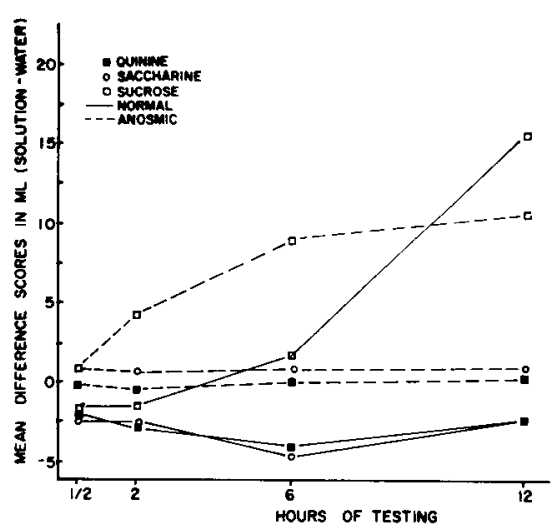

Fig. 4. Mean difference intake measures of sucrose, saccharin, and quinine solutions as a function of water deprivation. The 5 -min measurement interval was omitted since there were no reliable differences at that point. 

measurement interval. A number of studies have shown that the measurement interval used may significantly affect the results obtained (e.g., Wagner, 1968; Wagner, Green, \& Manley, 1965). The effects of measurement intervals are most clearly seen in the results of the second study of this paper. Figure 3 indicates a number of order-effect reversals as a function of the measurement interval.

The previous studies by these authors (Marks et al, 1969) indicated differential effects on the motivated performance of anosmic and normal rats as a function of previous of rats (anosmic, sham-operated, and normal) were trained in an active avoidance task; another three groups were trained in a passive avoidance task. The anosmic and normal rats from both studies were then used in an operant task. Normal rats did not differ as a function of previous experience. Passive-avoidance-trained anosmic rats responded reliably more than anosmic rats used in the active avoidance experiment, probably as a function of the familiarity with the food pellets used in both the reward training preceding passive avoidance and in the operant task. Neither of the present experiments was able to evaluate the possibility of differential effects of previous experience, but its possible contribution to the observed effects should not be ignored.

It would undoubtedly be possible to attribute some portion of the anosmic animal's performance to the loss of olfactory cues. Miller \& Erickson (1966) have shown taste solutions to have discriminable odors and have suggested that anosmia would affect preference by the elimination of these odors. The loss of olfactory cues
A second facotr is that of the experience. In that study, three groups

would not, however, explain a difference in relative preference between anosmic and normal animals as a function of different types of deprivation.

Since the olfactory bulbs project fibers to numerous parts of the limbic system and the limbic system is intimately connected with food and water regulation, the authors speculate that it is not merely the loss of olfactory cues, but primarily the loss of olfactory bulb input that may be the major factor accounting for the differences between anosmic and normal animals. Further research is clearly needed to determine the relationships among olfactory bulb input, limbic system function, and preference behavior.

\section{REFERENCES}

HONZIK, C. H. The sensory basis of maze learning in rats. Comparative Psychology Monographs, 1936, Whole No. 13 .

LINDLEY, S. B The maze learning ability of anosmic and blind anosmic rats. Journal of Genetic Psychology, 1930, 37, 245-267.

MARKS, $\dot{H}$. E. The effects of age, sex, and duration of confinement on activity wheel behavior. Unpublished MA thesis. Texas Christian University, 1968.

MARKS, H. E., REMLEY, N. R., SEAGO, J. D. \& HASTINGS, D. W. Effects of bilateral ablations of the olfactory lobes of rats on measures of learning and performance. Paper presented at the Southwestern Psychological Association, 1969.

MILLER, S. D., \& ERICKSON, R. P. The odor of taste solution. Physiology \& Behavior, 1966, 1, 145-146.

VANCE, W. B. Hypogeusia and taste preference behavior in the rat. Life Science, 1967, 6, 743-748.

WAGNER, M. W. Studies in comparative sugar preference in rodents: I. Methodology differences. Psychonomic Science, 1968, 11, 160.

WAGNER, M. W.. GREEN, K. F., \& MANLEY, $M$. B. Paired comparison method for measurement of sugar preference in squirrel monkeys. Science, $1965,148,1473-1474$.

\section{Intake differentiation by rats of equimolar sodium chloride and
lithium chloride solutions}

\author{
RONALD G. SMITH* \\ Wright State University, Dayton, Ohio 45431
}

Sodium chloride solutions have been frequently used in taste-aversion and bait-shyness experiments as taste equivalents or control solutions for lithium chloride toxin. It was demonstrated that rats can readily discriminate between $0.12 \mathrm{M} \mathrm{NaCl}$ and equimolar $\mathrm{LiCl}$ when both solutions are continuously available in their home cages. Additional work indicated that the learned discrimination was based primarily upon taste cues but that place cues could also be utilized.

Nachman (1963) established in rats a learned aversion to the taste of lithium chloride that could be

*The author thanks $S$. Siegel and $R$. DeForest for their assistance in conducting these studies. extinguished by repeated exposures to equimolar sodium chloride. The similarity of taste of these two salts is further supported by the similarity of nerve firing patterns recorded from the chorda tympani (Beidler, 1953;
Fishman, 1957) and subjective reports of humans (Hanlon, Romaine, Gilroy, $\&$ Deitrich, 1949). Several studies have since employed $\mathrm{LiCl}$ poisoning and have utilized equimolar $\mathrm{NaCl}$ as a control solution (Garcia \& Koelling, 1966) or have alluded to salt taste generalization effects (Kalat \& Rozin, 1970). Thus, there has appeared to be a growing acceptance of taste equivalence for these salts in rats. However, Nachman clearly indicated that 10 -min test periods may have been too brief to clearly reveal a discrimination between $\mathrm{NaCl}$ and $\mathrm{LiCl}$. He noted that during the last half of the test period there appeared to be some beginning signs of a preference for $\mathrm{NaCl}$ over $\mathrm{LiCl}$. This possible preference was attributed to "learning based upon the position of the tubes within each daily 10-min test [Nachman, 1963, p. 347]." Since the toxic effects of $\mathrm{LiCl}$ are fast acting, it is possible that aversion responses could develop in less than $10 \mathrm{~min}$. However, Barnett (1963) and Garcia \& Koelling (1966) report that poisoning-aversion learning for very distinctive environments is extremely difficult, if not impossible, to obtain in the rat. In the following experiments, rats were confronted with the problem of having only $\mathrm{NaCl}$ and $\mathrm{LiCl}$ available to drink. If the animals were to avoid the toxic aftereffects of $\mathrm{LiCl}$, they must learn either the difficult taste discrimination or the difficult place discrimination. After discrimination learning had occurred, it was possible, by manipulating bottle position and test duration, to determine the utilization of place or taste cues in the choice of solutions.

\section{METHOD}

Throughout the first experiment the nine male $300-$ to $450-\mathrm{g}$ Sprague-Dawley rats were housed in their individual home cages and had ad lib access to Purina Lab Chow. Animals were adapted to the cages for 7 days prior to being given the salt solutions. During the adaptation period each cage had two standard water bottles attached. Water intake was recorded daily at 12:00 noon. At the end of the seventh adaptation day, two Ss were eliminated for displaying a water-bottle side preference of more than $5: 1$ on at least 1 day. Of the remaining seven Ss, four had mean left preferences of up to $75 \%$, one had no side preference, and two had mean right preferences of up to $70 \%$. The $0.12-\mathrm{M}$ solutions were prepared with distilled water. $\mathrm{LiCl}$ bottles were located on the preferred side for half of the Ss and on the nonpreferred side for the other half. Identical bottles, stoppers, and drinking tubes were used on each cage. Ss had continuous access 